\title{
Emerging Biosorption, Adsorption, Ion Exchange, and Membrane Technologies
}

\section{J. Paul Chen, Lawrence K. Wang, Lei Yang, and Soh-Fong Lim}

\section{CONTENTS}

INTRODUCTION

EMERging Biosorption for HeAvy Metals Removal

Magnetic Ion Exchange Process

Liquid MEMBRANE PROCESS

EMERging TeChNOLOGIES FOR ARSENIC REMOVAL

NOMENCLATURE

REFERENCES

\section{INTRODUCTION}

In the last $20 \mathrm{yr}$, the water industry has been faced with a series of great challenges. Industries have discharged wastewater that contains various new compounds. In addition, the demand for high-quality water has been significantly increasing. As a result, new water treatment technologies have been developed. In this chapter, three novel technologies are introduced. The emerging technologies for the removal of heavy metals, disinfection byproducts, total organic carbons (TOC), and arsenic are illustrated.

\section{EMERGING BIOSORPTION FOR HEAVY METALS REMOVAL}

Sorption or adsorption is a gas-solid or liquid-solid phenomenon defined as the accumulation of particular component(s) at the surface between the two phases. Unbalanced forces of attraction between the gas or liquid and solid phases result in an increase of concentration of the particular component(s) on the solid phase. Sorption can be categorized into physical sorption and chemisorption based on the strength of these forces. Physical sorption involves only relatively weak forces, whereas in chemisorption a chemical bond is formed between the sorbate components and the sorbent components on the solid surface. In the past several decades, a dramatic increase of metal contaminant volume has posed many serious environmental problems. The most common treatment process such as precipitation and ion-exchange are usually effective in reducing the extent of contamination, but are not economical. Removal by various sorbents, such as activated carbon, has emerged as one of the most effective technologies for removing organic and inorganic pollutants from water and wastewater. The manufacture of sorbents 